\title{
Application of satellite Remote Sensing for Urban Risk Analysis: a case study of the 2003 extreme heat wave in Paris
}

\author{
Bénédicte Dousset \\ Hawaii Institute of Geophysics and \\ Planetology \\ University of Hawaii, Honolulu, USA \\ bdousset@hawaii.edu
}

\author{
Françoise Gourmelon \\ Laboratoire Géomer \\ CNRS UMR-6554, Institut \\ Universitaire Européen de la Mer \\ Plouzané, France \\ Francoise.Gourmelon@univ-brest.fr
}

\author{
Elena Mauri \\ Istituto Nazionale di Oceanografica e \\ di Geofisica Sperimentale \\ Trieste, Italy \\ emauri@ogs.trieste.it
}

\begin{abstract}
Satellite observations are used to monitor the August 2003 heat wave in Paris, and their applications to environmental risk assessment and to health alert systems are discussed. Fifty NOAA-AVHRR satellites images were processed to retrieve the diurnal variations of surface temperature. Land cover classification of the Paris basin was mapped from a multispectral SPOT-HRV image. Geographic Information Systems were used to merge SPOT-HRV and NOAA-AVHRR data. Results indicate large surface temperature gradients and contrasted warming patterns. Contrary to prevailing concepts, the magnitudes of temperature anomalies are larger in daytime than at night. Surface temperature gradients between urban parks and industrial areas are largest in daytime, the negative correlation between surface temperature and normalized vegetation index showing the cooling effect of vegetation. The temperature difference between downtown and suburban areas is largest at night, revealing the strong relationship of nighttime temperature anomaly with built density inferred from the classified SPOT image. Comparison between time-series for August 1998, a normal summer, and the anomalous August 2003, indicates a large difference in diurnal temperature amplitude, confirming the impact of high nighttime temperatures on the heat wave process. The areas of the Paris region most vulnerable to heat stress were identified. Thermal indices can be constructed for assimilation into logistic models, to assess the urban variability of risk factors and implement health alert systems. The method is general and applicable to other cities.
\end{abstract}

\section{INTRODUCTION}

Numerous heat waves have occurred over the past twenty years, in cities such as Athens (1987), London and Seville (1995), and Chicago (1995 and 1999). In summer 2003, a persistent anticyclone over Western Europe blocked rainbearing depressions from the Atlantic Ocean and advected hot air northward from North Africa. Average summer temperatures exceeded the $1961-90$ mean by $\sim 3^{\circ} \mathrm{C}$ (5 standard deviations) [1]. These anomalous conditions resulted in a heat-wave of exceptional strength and duration, and mortality in excess of 30,000. Global warming may result in further increases of European Summer temperature anomalies, heat waves and droughts, and in ensuing mortality [2].

Heat waves are especially deadly in cities due to their specific surface characteristics: decrease of surface moisture available for evapo-transpiration, changes in radiative fluxes and near surface flow, and anthropogenic heat and pollutants. At night, urban areas release the heat stored in the built structures, while outgoing radiation decrease temperatures in rural areas. It is the lack of relief at night, rather than high daytime temperatures, that constitute a human health risk. Air pollution exacerbates the adverse health effect of higher temperatures, by stressing the respiratory and circulatory systems. The elderly, infants, young children, and people with chronic health problems, are most at risk.

In August 2003, the Paris basin experienced nine consecutive days with maximum daytime air temperatures reaching $38^{\circ} \mathrm{C}$, and with minimum nighttime temperatures steadily increasing from 20 to $25.5^{\circ} \mathrm{C}$ at the peak of the heat wave on August 12. The anticyclonic conditions combined with the emission of pollutants triggered an increase of ozone, nitrous oxide and particles concentration. The heat stress resulted in 4,867 heat-related fatalities for the Paris basin alone, corresponding to a mortality increase of $60 \%$ [3].

Air surface temperatures were probably underestimated, since they were recorded at a weather station in Montsouris Park, away from the influence of the built environment. As in most cities, the weather station network is also too sparse to resolve small scale temperature variations, best resolved by satellite images. Previous studies using satellite remote sensing have shown the relationship between sprawling conurbations and complex temperature anomalies patterns, evidenced by the spatial variability of Land Surface Temperature (LST) [4]. However, satellite data have not been used previously to observe heat wave factors in urban areas, evaluate risks, and implement alert systems. 


\section{DATA ACQUISITION AND PROCESSING}

Studies of urban heat waves require repetitive imaging at high spatial resolution. From 4 to 13 August 2003, there were only one image from LANDSAT-5 Thematic Mapper (on 9 August), one from Terra-ASTER (on 10 August), and only two daily from MODIS, insufficient to resolve the diurnal cycle. In contrast, three NOAA satellites operating simultaneously (NOAA-12, -16 and -17) provide up to 6 images per day, fully resolving the diurnal temperature cycle. The NOAA images were acquired at the receiving station of the Istituto Nazionale di Oceanografica e di Geofisica Sperimentale, in Trieste.

Fifty NOAA-AVHRR images with small zenithal viewing angles were selected, to ensure ground resolution close to 1.1 $\mathrm{km}$, and minimize anisotropic effects. The images were geometrically corrected for earth rotation and curvature, and interactively referenced to a Lambert projection. The AVHRR scans in five spectral channels, centered at $0.62 \mu \mathrm{m}, 0.91 \mu \mathrm{m}$, $3.74 \mu \mathrm{m}, 10.8 \mu \mathrm{m}$ and $12 . \mu \mathrm{m}$. For each satellite pass, an image was produced for each channel. Land albedo and daytime cloudiness were derived from channel 2, and nighttime cloudiness from the difference between channels 3 and 4 . Cloudy pixels were flagged based to a threshold derived from the histograms of cloud-free images. Normalized Difference Vegetation Indices (NDVI) were computed from channels 1 and 2. The differential atmospheric attenuation of infrared channels 4 and 5 [5] suggested a negligible water vapor correction. The objective being to study temporal variations of land surface temperatures (LST), emissivity corrections were neglected, being time-independent.

Images of LST, averaged over the period of interest, were constructed for the times intervals of the NOAA satellites passes (i.e. 1-4, 4-7, 9-12, 12-15, 15-18, 20-23 UTC); the images distribution and the time intervals are shown in Fig. 1.

Surface temperature, a driving parameter that controls mixing in the urban canopy layer, is closely related to the surface energy balance, in turn governed by surfaces characteristics and properties. Those were extracted from a SPOT-4 High Resolution Visible (HRV) multi-spectral image, acquired on July 13 2003, three weeks before the extreme event. The SPOT image processing included detector radiometric equalization, geometric processing to remove the earth rotation, and resampling across-track to a uniform 20-m pixel size. An unsupervised land cover classification was derived from the four visible and near infrared channels, yielding 6 classes corresponding to water, densely built urban, suburban residential, light bare soils, densely vegetated (forest, lawns), and fields (Fig. 3). The classification was validated using the NDVI, calculated from the visible and near-infrared channels.

A Geographic Information System was used to generate land use / cover fractional images, and to merge the 20-m SPOT pixel, with the 1-km AVHRR. Additional atmospheric data were obtained from the air quality agencies of AIRPARIF and Météo-France. Human health and mortality statistics were provided by the French health agency: "Institut national de Veille Sanitaire” [6].

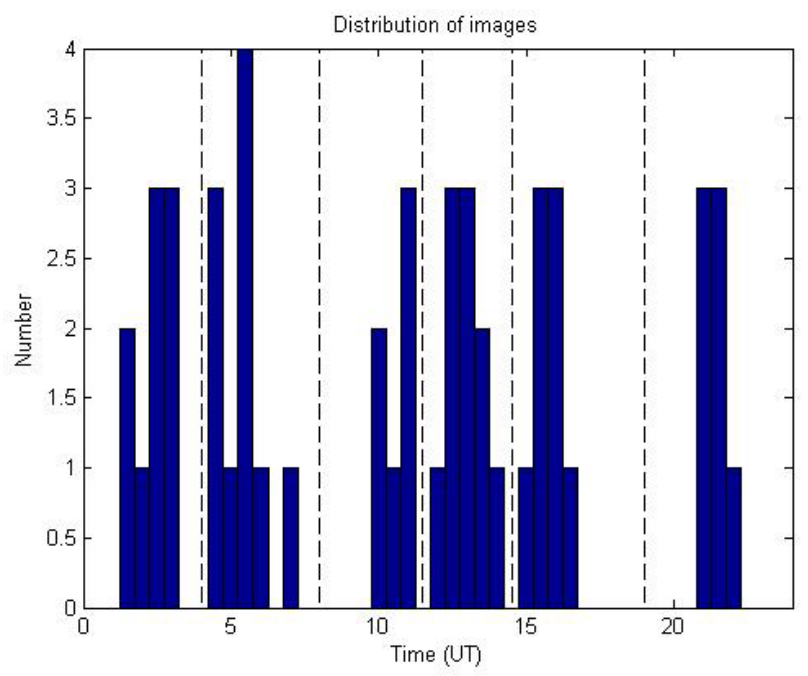

Fig. 1 The 24 hour time distribution of the 50 images sensed by NOAA satellites 12, 16 and 17, over the Paris basin, from 4 to 13 August 2003.

\section{RESULTS}

\section{A. Spatial variability of Land Surface Temperature}

Fig. 2 displays the diurnal cycle of LST averaged over the nine days of the heat wave. Each image is a composite of 8 or 9 images for the 6 time intervals of the NOAA satellites passes indicated in Fig. 1. These images clearly illustrate the spatial variability of LST over the diurnal cycle. They reveal contrasted nighttime and daytime patterns, reflecting the different rate of radiant cooling and heating between the rural and urban areas, enhanced by the stable atmosphere and low wind which characterized the heat wave episode.

The 1-4 UTC time range image shows an $8^{\circ} \mathrm{C}$ heat island concentrated in downtown Paris. The parks of Boulogne and Vincennes at the western and eastern limits of Paris, respectively, and the suburban and rural surfaces rapidly cool due to evapo-transpiration and unobstructed fields of view. On the contrary, in downtown Paris, buildings and streets cool slowly, due to the lack of moisture availability and to the trapping of long wave radiation within urban canyons. In the 4-7 UTC time range image, downtown Paris is slightly cooler. At night, the LST gradient is well correlated to the distribution of built density (Fig. 3).

During the day, multiple temperature anomalies are scattered in the densely built and/ or industrial suburbs, reflecting mostly variations of the surface heat balance between dry and moist surfaces. In the 12-15 UTC image, a $11^{\circ} \mathrm{C}$ temperature anomaly is observed and the highest LST reaches $38^{\circ} \mathrm{C}$ to $41^{\circ} \mathrm{C}$. The rapid warming results from the surfaces low thermal inertia and open spaces. In downtown Paris, LST is slightly cooler $36^{\circ} \mathrm{C}$ to $38^{\circ} \mathrm{C}$. The coolest areas include the urban parks and the vicinity of the Seine River $34^{\circ} \mathrm{C}$ to $36^{\circ} \mathrm{C}$. 

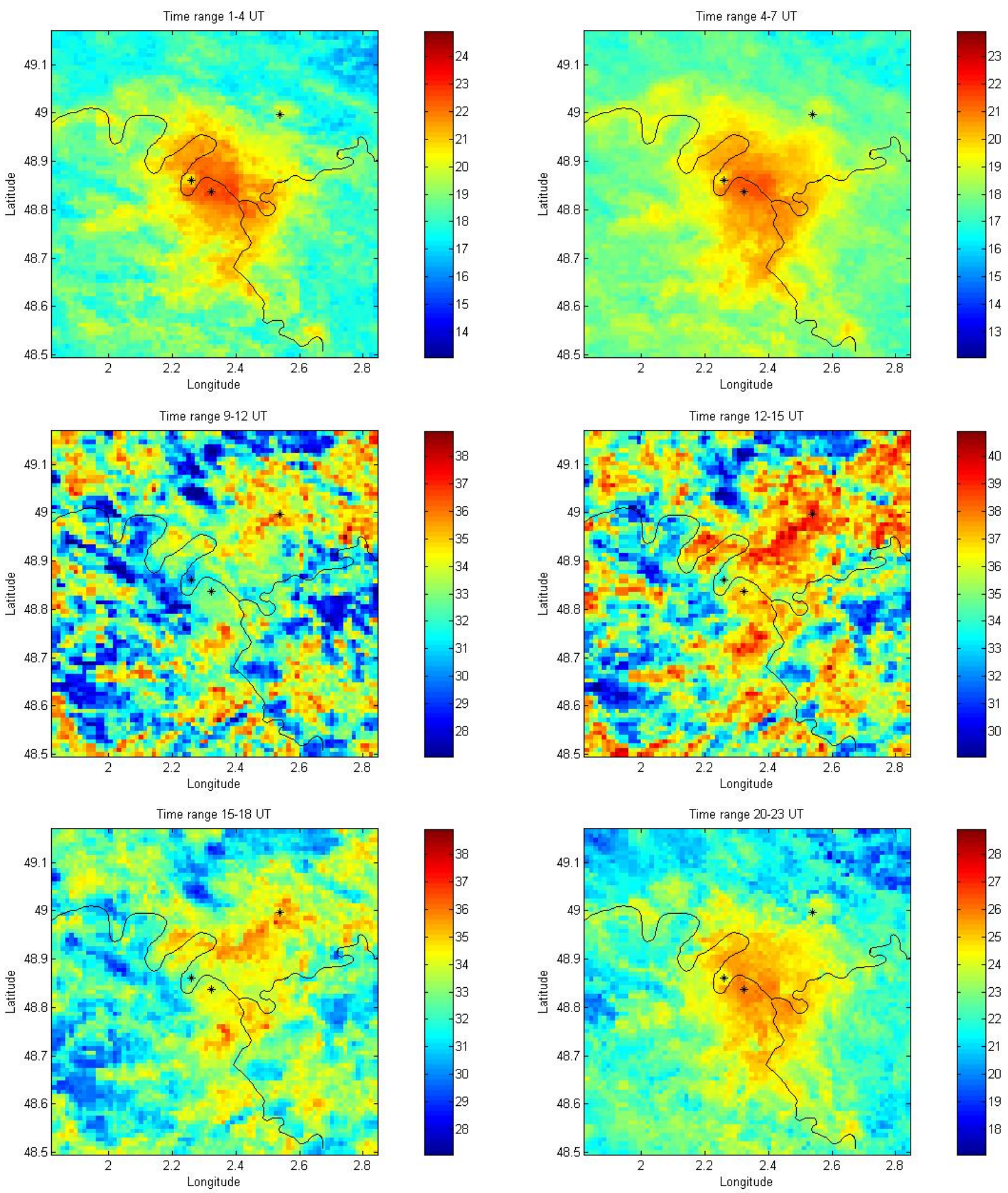

Fig. 2 Average Land Surface Temperature infrared images over the heat wave event of August 4 to 13, 2003, for each of the diurnal time intervals shown in Fig. 1. The color scales are in degrees Celsius. The three points used to construct Fig. 4 are shown by *; to the West in Bois de Boulogne, in the center in downtown Paris, and to the North in an industrial site. 

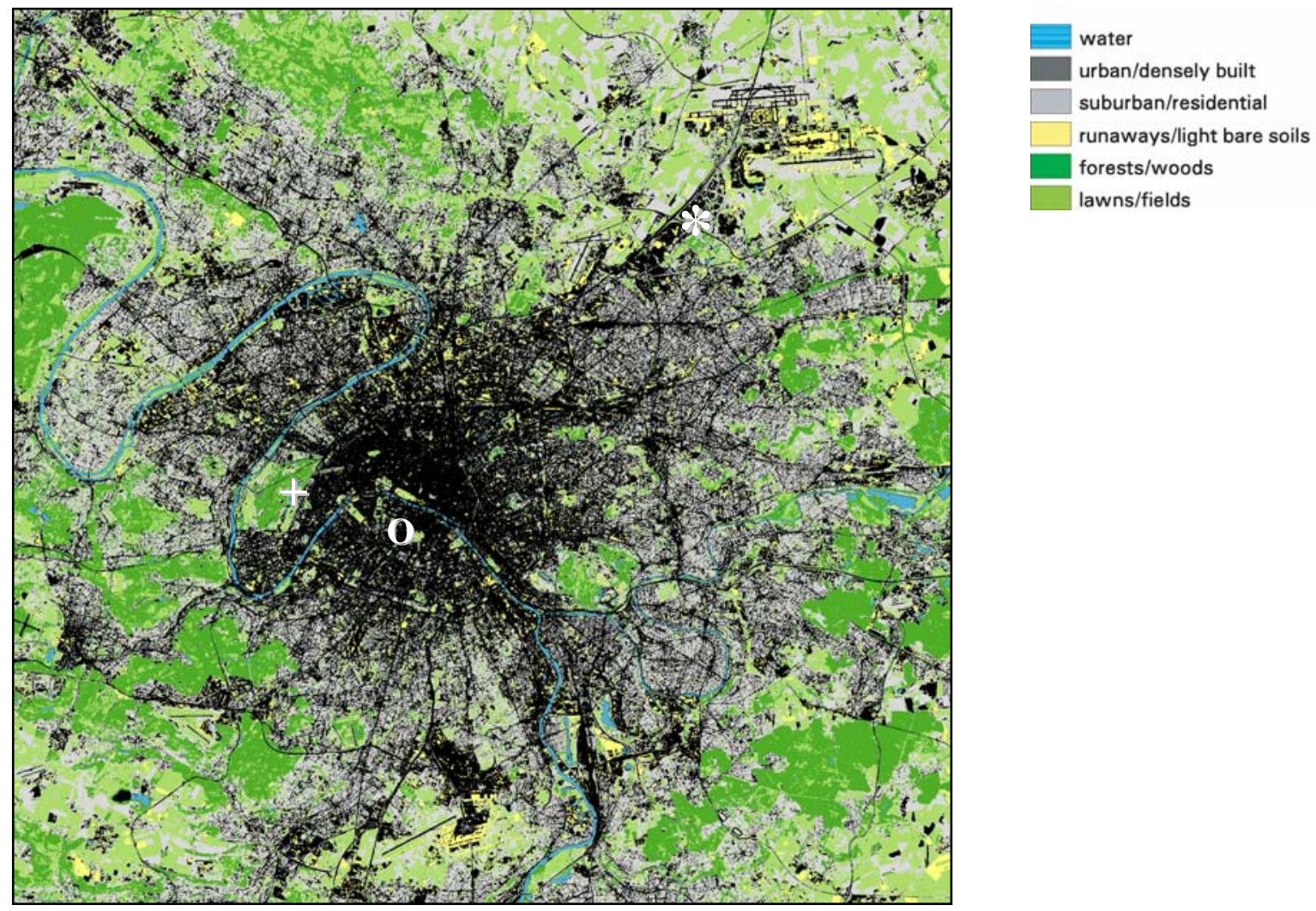

Fig. 3 Land cover classification of Paris derived from a SPOT-4 HRV image on July13, 2003. Symbol * represents the industrial site, o downtown Paris, and + the Boulogne Park, at which points the mean diurnal cycle of Land Surface Temperature is shown in Fig.4.

\section{B. Mean diurnal cycles at different locations}

Maximum and minimum LST and amplitude of the diurnal cycle were derived from the composite images. Fig. 4 displays the mean diurnal cycle of LST at three locations (downtown Paris, an industrial site near Roissy Airport, and the Boulogne urban park). The LST diurnal cycle indicates a near constant difference of $\sim 1.5^{\circ} \mathrm{C}$ to $2.2^{\circ} \mathrm{C}$ between downtown and the park, but differences of $-3^{\circ} \mathrm{C}$ at night, and $+3.5^{\circ} \mathrm{C}$ at noon between downtown and the industrial site which has a lower thermal inertia, and $+4.5 \mathrm{C}$ at noon between the latter and the park. Since industrial surfaces have a lower thermal inertia, they are warmer in daytime and cooler at nighttime than the downtown and parks areas (Fig.5). Similar patterns were observed in a previous analysis of the 1998 summer [4], although lower minimum nighttime LST averted the occurrence of a heat wave.

\section{Land Surface Temperature and vegetation}

In spring 2003, both the strong incident radiation and large precipitation deficit progressively reduced the moisture content of the soil, lessening the surface latent heat flux and enhancing the sensible heat flux, thus contributing to high temperatures. Indeed, the vegetation index (NDVI) was lower in August 2003 than 1998, reflecting drier conditions. Fig. 6 represents the bivariate histogram of the LST afternoon composite image of August 2003, versus the NDVI. It indicates a negative correlation, with a slope of $2^{\circ} \mathrm{C}$ per NDVI unit. In early afternoon, the LST difference did not exceed $2.2^{\circ} \mathrm{C}$ between downtown and the Boulogne Park, and $3.8^{\circ} \mathrm{C}$ between the later and the industrial suburb. Although, in the afternoon the LST in the urban park were relatively similar in August 1998 and 2003, at night they were $2^{\circ} \mathrm{C}$ higher in 2003 than in 1998.

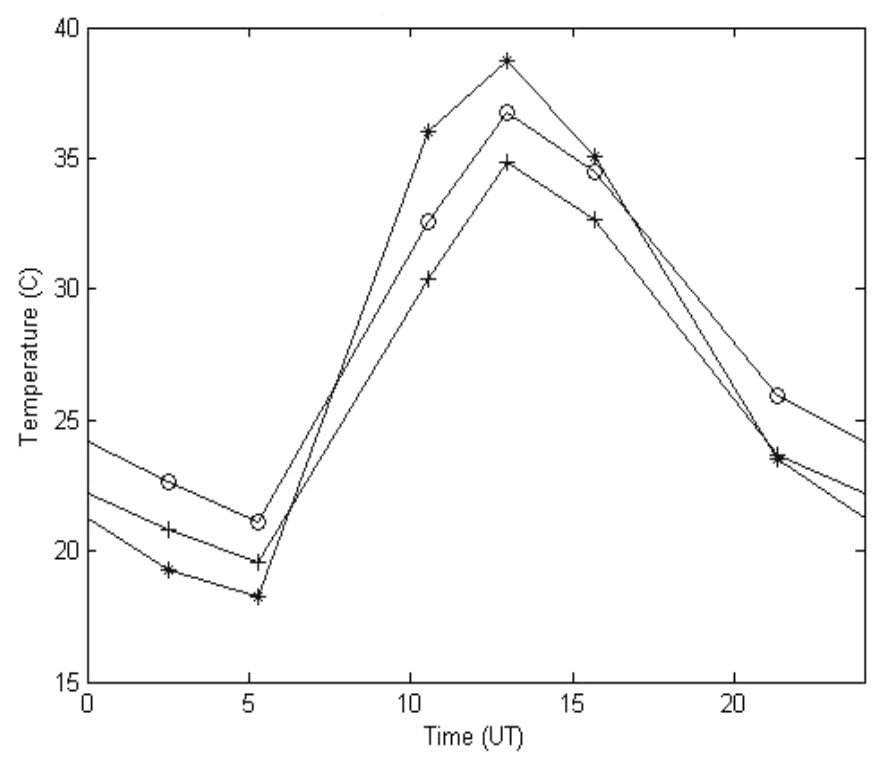

Fig. 4 Mean diurnal cycles of Land Surface Temperature, constructed from the 50 NOAA-AVHRR images of August 4-13 2003, * at an industrial site, $\boldsymbol{o}$ in downtown Paris and + at the Boulogne Park seen in Fig.3. 


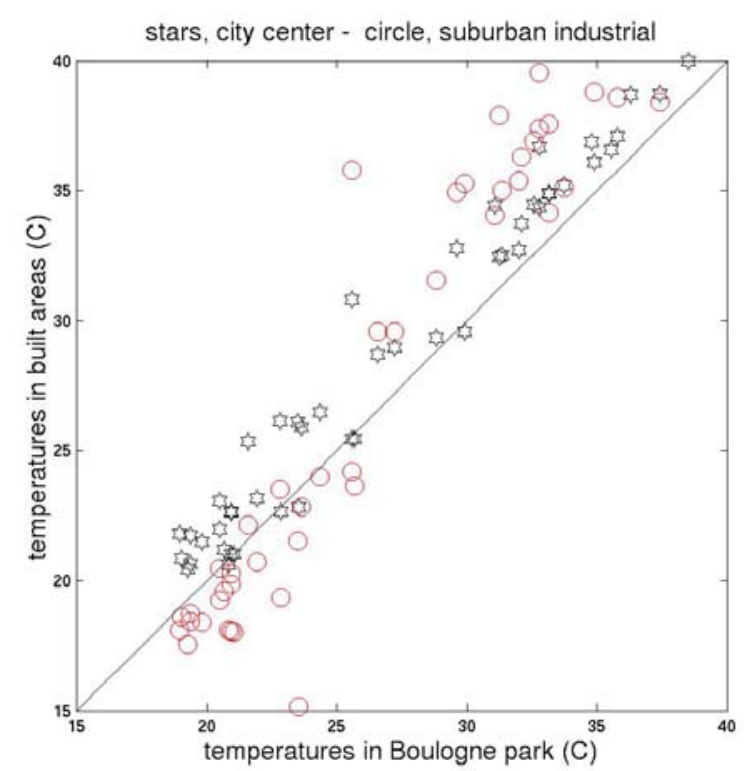

Fig. 5 Land Surface Temperature of built areas (downtown and industrial suburb) versus that of park.

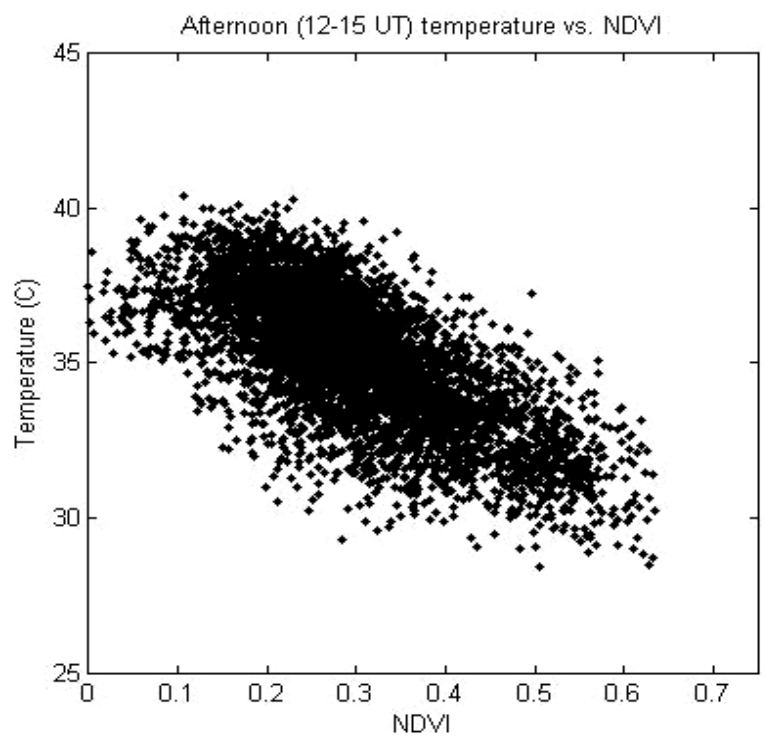

Fig. 6 Bivariate histogram of the Paris basin Land Surface Temperature in the 12-15 UTC range, August 4 to 13 2003, versus the NDVI.

\section{DISCUSSION}

Results have shown contrasted microclimate patterns: a significant nocturnal heat island in downtown Paris related to built density and lack of evapo-transpiration; and multiple daytime thermal anomalies scattered over industrial suburbs related to low thermal inertia and unobstructed field of view. These variations of surface temperature gradient can only be resolved by high resolution images, with temporal sampling at least six times per diurnal cycle, as is possible from the AVHRR when three NOAA satellites are available simultaneously. The patterns of surface temperatures, at noontime, in AVHRR images agree well with those derived from a $120 \mathrm{~m}$ resolution LANDSAT-5 TM thermal image of August 9 at 12:17 [7], but the AVHRR offers a temporal resolution unachievable with the 30-day repeat cycle of LANDSAT.

Comparison between time-series for August 1998, a normal summer, and August 2003, confirms the impact of high nighttime temperatures on urban heat wave process. Combining SPOT and AVHRR data, the regions of metropolitan Paris areas most vulnerable to heat stress have been identified.

Satellite thermal data at the start of this extreme event, would have helped to efficiently map the areas more exposed to heat stress and excess of mortality, and issue appropriate warning. Thermal indices can be constructed from satellite data and assimilated into logistic models, to estimate the spatial variability of risk factors and implement health alert systems. Presently, the temperature reference for heat wave alerts remains Montsouris Park, which is not representative of the urban environment. Although Paris was chosen as a case study, having recently experienced an extreme heat wave with well-documented health consequences, the method is general and should be applicable to other cities as well.

\section{ACKNOWLEDGMENT}

This work was funded by a research fellowship from the National Research Council and the National Oceanic and Atmospheric Administration. The work was conducted at the NOAA Atmospheric Resources Lab in collaboration with the Géomer Laboratory, UMR-6554 of the CNRS. Discussions with Julian Wang are gratefully acknowledged.

\section{REFERENCES}

[1] C. Schar, P.L.Vidale, D. Luthi, C. Frei., C. Haberli, M.A. Liniger, and C. Appenzeller, "The role of increasing temperature variability in European summer heat waves,” Nature, 427, 6972, pp. 332 -335, 2004.

[2] G. A. Meelh, and C. Tebaldi, “More intense, more frequent, and longer lasting heat waves in the 21st century,” Science, 305, 5686, pp. 994-997, 2004.

[3] S. Vandentorren, F. Suzan, M. Pascal, M., A. Maupoix, et S. Medina, "Données météorologiques et enquétes sur la mortalité dans 13 grandes villes françaises”. Bulletin Epidemiologique Hebdomadaire, 45-46, 219220, 2003.

[4] B. Dousset, and F. Gourmelon, "Satellite multi-sensor data analysis of urban surface temperatures and landcover," ISPRS Journal of Photogrammetry and Remote Sensing, 58, 43-54, 2003.

[5] E. P. McClain, W.G. Pichel, C.C. Walton, "Comparative performance of AVHRR-based multichannel sea surface temperatures” Journal of Geophysical Research, 90 (C6), pp. 11587-11601, 1985.

[6] M. Ledrans, "Impact sanitaire de la vague de chaleur d'août 2003 en France, bilan et perspectives". Rapport de l'Institut national de Veille Sanitaire, 2003.

[7] M. Ledrans, S. Vandentorren, P. Bretin, et Alice Croisier, "Etude des facteurs de risque de dècés des personnes agées résidant à domicile durant la vague de chaleur d'août 2003”. Rapport de l'Institut national de Veille Sanitaire, 2004. 
2007 Urban Remote Sensing Joint Event 